\title{
Rigid Endoscopic Examination of Neonatal Larynx in OPD as a Screening Procedure
}

Harish Chandra Reddy Pingili, S Ramesh Kumar

\begin{abstract}
Objectives/hypothesis: To describe a novel method of examination of neonatal larynx, using a $70^{\circ}$ rigid $4 \mathrm{~mm}$ fiber optic endoscope in OPD as a screening procedure for evaluation of neonatal stridor/hoarse cry.
\end{abstract}

Study design: Examination technique and safety profile of a novel method of examination of neonatal larynx in OPD using widely available $70^{\circ}$ rigid $4 \mathrm{~mm}$ endoscope.

Results: Ten neonates, underwent laryngoscopy as described below, whose age and weight in kilograms were recorded. The pulse rate, $\mathrm{O}_{2}$ saturation levels and mean arterial pressure were recorded during the procedure to know the effect of the procedure on hemodynamics and respiration of the neonates. Time taken for the procedure for satisfactory view of larynx is also recorded and tabulated.

Conclusion: The novel method of examination of neonatal larynx using $70^{\circ} 4 \mathrm{~mm}$ rigid endoscope in OPD/ward is a safe procedure and gives excellent view/recording of neonatal larynx in its native anatomical and functional status.

Keywords: Neonate, Neonatal laryngoscopy, $70^{\circ} 4 \mathrm{~mm}$ rigid endoscope.

How to cite this article: Pingili HCR, Kumar SR. Rigid Endoscopic Examination of Neonatal Larynx in OPD as a Screening Procedure. Int J Phonosurg Laryngol 2012;2(2): 74-76.

\section{Source of support $\mathrm{Nil}$}

Conflict of interest: None declared

\section{INTRODUCTION}

Clinical examination of neonatal larynx is always a challenge, which may require hospitalization and occasionally is done in an operation theater under anesthesia. ${ }^{1}$ Direct laryngoscopy under general anesthesia using a laryngoscope is the primary technique for evaluation of laryngeal disease in neonates, in most of the centers. U se of a laryngoscope with its blade in valleculla, which lifts the epiglottis up, distorts the anatomy of the larynx because of which, moments of the vocal cord (spelling corrected) cannot be assessed accurately. ${ }^{2}$ U se of an anesthetic with a muscle relaxant interferes with the function of the larynx and administration of general anesthesia to neonate is al ways considered a risky procedure. The advantages of awake endoscopic examination compared to examination under general anesthesia include the ability to perform the examination expediently in the office setting with the parents present, without the need for sedation, leading to less medical expense. ${ }^{3}$ In this paper, we present our early experience with a novel method of awake endoscopic evaluation of neonatal larynx, which is minimally invasive and provides excellent visualization of neonatal larynx. The procedure is safe enough to be used in clinic/OPD.

\section{MATERIALS AND METHODS}

1. $4 \mathrm{~mm} 70^{\circ}$ standard nasal endoscope, camera and a recording facility.

2. Multiparameter monitor capable of recording subject's $\mathrm{SPO}_{2}$, pulse rate and blood pressure.

3. Intubation kit and drugs for resuscitation in emergency.

4. A neonatal anesthetist as stand by.

Ten neonates who were referred from our new born intensive care unit for evaluation of inspiratory stridor were included in this study. Of them seven were male and three were female neonates. A ge of the subjects ranged from 4 to 30 days and their weight ranged from 1.70 to $4.0 \mathrm{~kg}$.

\section{PROCEDURE}

The baby is placed in supine position on the examination table and suitably restrained in a towel. The neonate's mouth is kept open by insinuating examiners left index finger between the jaws of the neonate on left side. The head is restrained by the thumb and rest of the fingers of left hand and slightly extended (Fig. 1).

The endoscope is taken in the right hand of examiner with its bevel facing forward. The tip of the $70^{\circ} 4 \mathrm{~mm}$ rigid endoscope is passed between both jaws and gently advanced over the base of tongue into hypopharynx and is gently maneuvered to visualize the larynx during the gag reflex. $\mathrm{No}$ attempt is made to restrict the tongue movements of the neonate, with the left index finger of examiner which is in between the gums of the neonate. No attempt is made to forcefully visualize the larynx by rigorously moving the endoscope. The examiner shall patiently wait till the neonate gags up to show the larynx (Fig. 2). Excessive secretions in the pharynx during the procedure may be aspirated through a small catheter passed through the nose.

U sually satisfactory visualization of larynx is completed in less than 1 minute. Recording facility is advised so that it can be reviewed again. No surface anesthetic is used which 
Rigid Endoscopic Examination of Neonatal Larynx in OPD as a Screening Procedure

Table 1: Variation of selected parameters during the procedure in each neonate and time taken for satisfactory visualization of larynx

\begin{tabular}{|c|c|c|c|c|c|c|c|c|c|c|c|}
\hline $\begin{array}{l}\text { S. } \\
\text { no. }\end{array}$ & $\begin{array}{l}\text { Name of } \\
\text { the baby }\end{array}$ & Sex & $\begin{array}{l}\text { Age in } \\
\text { days }\end{array}$ & $\begin{array}{l}\text { Weight } \\
\text { in kg }\end{array}$ & $\begin{array}{l}\text { Pre } \\
\text { VLS } \\
\mathrm{SPO}_{2}\end{array}$ & $\begin{array}{l}\text { Post } \\
\text { VLS } \\
\mathrm{SPO}_{2}\end{array}$ & $\begin{array}{l}\text { Pre } \\
\text { VLS } \\
\text { pulse }\end{array}$ & $\begin{array}{l}\text { Post } \\
\text { VLS } \\
\text { pulse }\end{array}$ & $\begin{array}{l}\text { Pre } \\
\text { VLS } \\
\text { MAP }\end{array}$ & $\begin{array}{l}\text { Post } \\
\text { VLS } \\
\text { MAP }\end{array}$ & $\begin{array}{l}\text { Time } \\
\text { taken } \\
\text { in sec }\end{array}$ \\
\hline 1 & B/O M ounika & $\mathrm{F}$ & 04 & 2.50 & 88 & 89 & 154 & 149 & 43 & 45 & 36 \\
\hline 2 & B/0 Swapna & $M$ & 06 & 2.70 & 100 & 100 & 164 & 182 & 52 & 47 & 39 \\
\hline 3 & B/O Laxmi & M & 09 & 1.70 & 99 & 98 & 117 & 107 & 24 & 36 & 31 \\
\hline 4 & $\mathrm{~B} / 0 \mathrm{~K}$ avitha & $M$ & 09 & 3.00 & 94 & 94 & 107 & 151 & 59 & 91 & 27 \\
\hline 5 & B/O Divya & $\mathrm{F}$ & 13 & 2.50 & 91 & 91 & 116 & 108 & 52 & 69 & 34 \\
\hline 6 & B/O Rajitha & $\mathrm{F}$ & 21 & 2.25 & 93 & 92 & 143 & 127 & 45 & 41 & 33 \\
\hline 7 & B/O Y akamma & $M$ & 27 & 2.25 & 99 & 99 & 128 & 130 & 54 & 37 & 29 \\
\hline 8 & B/O Y akamma & $M$ & 27 & 2.28 & 99 & 99 & 128 & 113 & 49 & 49 & 43 \\
\hline 9 & B/O Rajitha & M & 28 & 4.00 & 100 & 98 & 167 & 166 & 49 & 64 & 46 \\
\hline 10 & B/O Renuka & $M$ & 30 & 2.00 & 96 & 94 & 128 & 115 & 57 & 72 & 43 \\
\hline
\end{tabular}

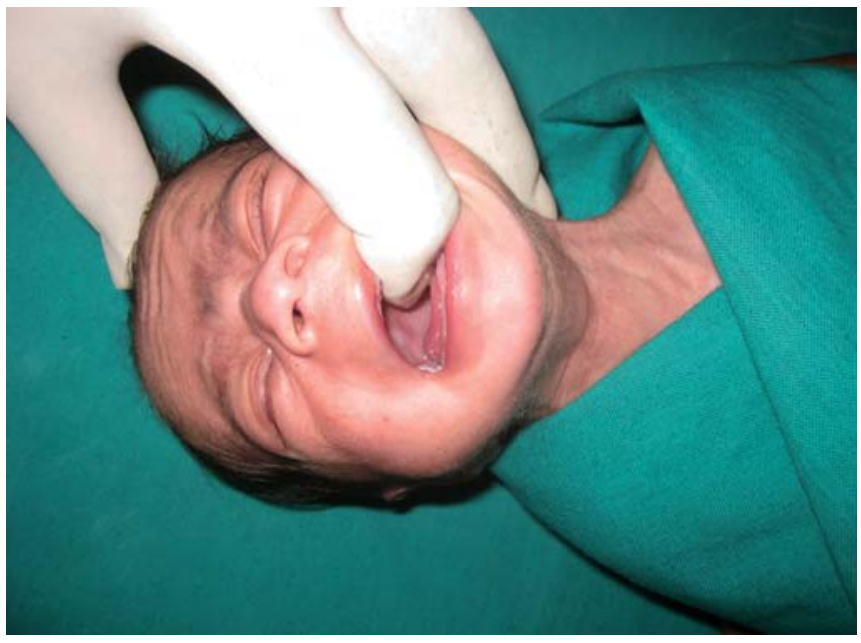

Fig. 1: Position of the neonate for laryngoscopy. Note: The finger between both jaws on left side does not restrict tongue movements

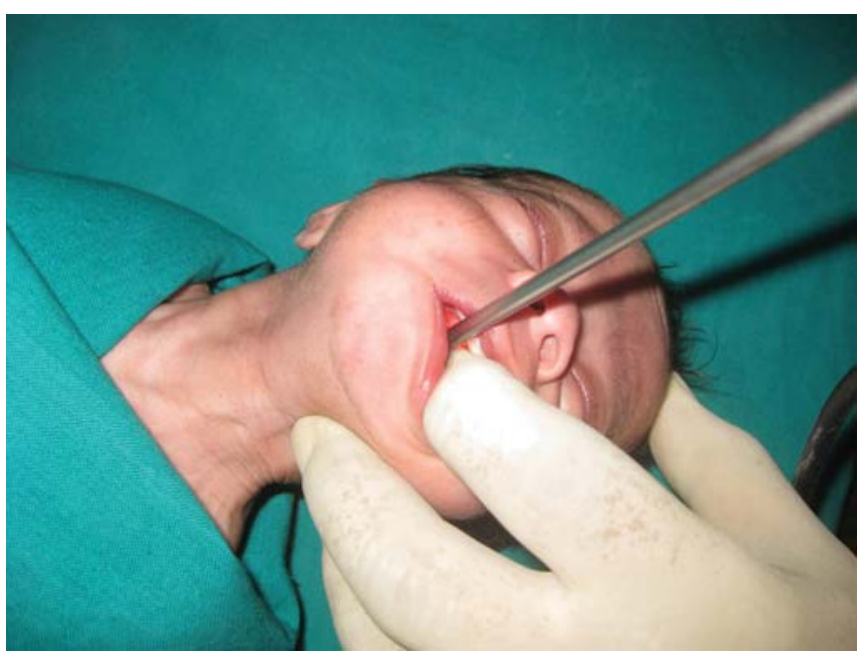

Fig. 2: Position of the endoscope during the procedure

would suppress the gag reflex. NBM period for 2 hours is advised prior to procedure. $\mathrm{SPO}_{2}$, pulse rate and mean arterial pressures were noted before and after the procedure. The parameters were tabulated as shown in the Table 1 as

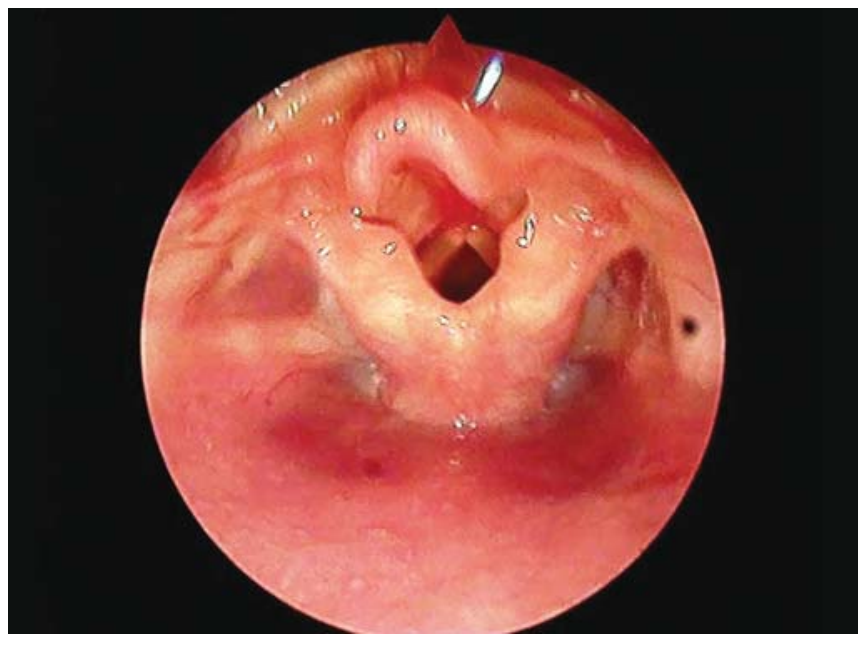

Fig. 3: The neonatal larynx recorded during laryngoscopy done as described in the article

per the age of the neonates in ascending order. Each parameter variation due to procedure was statistically eval uated. Time taken for satisfactory visualization of larynx for each neonate is recorded.

\section{RESULTS}

Excellent visualization of larynx was obtained in all neonates. The time taken for satisfactory visualization of the larynx ranged from a minimum of 27 seconds to a maximum of 46 seconds. There is no incidence of regurgitation of food during the procedure. No procedure was abandoned due to any complication. All procedures and postexamination periods were uneventful (Fig. 3).

\section{DISCUSSION}

Our early experience with this new technique of endoscopic neonatal laryngoscopy shows that it is a safe and feasible procedure which can be done in a clinic or OPD, as a primary 
screening procedure in evaluation of stridor or hoarse cry in a neonate.

The approach is less invasive and less traumatic than other procedures of direct laryngoscopy under general anesthesia with (or) without use of a rigid endoscope. Flexible endoscopes are not widely available, ultra thin neonatal flexible laryngoscopes do not have a suction port. Disadvantages of flexible fibre optic laryngoscopes are that they are high in cost and the instrument is very delicate. $M$ aintenance and sterilization costs are very high. ${ }^{4}$ The $70^{\circ}$ endoscope used in this procedure may also be connected to a standard stroboscope which provides additional information, especially in vocal cord paresis. ${ }^{4}$

\section{CONCLUSION}

The per oral rigid $70^{\circ}$ endoscopic examination of larynx without fixing the tongue in neonates is more satisfactory than other methods of examination, in terms of cost of equipment and safety profile. The examination can be safely undertaken in OPD as a routine screening procedure for evaluation of neonatal stridor or hoarse cry.

\section{REFERENCES}

1. Textbook of pediatric otolaryngology Head and neck surgery by Cris de Souza, (Singular publishing group inc.) 1:30-32.

2. Pediatric Otolaryngology (4th ed) (Bluestone and others) 2: 1385-90 (Saunders).

3. Flint: Cummings otolaryngology, head and neck surgery (5th ed), section 6 Chapter 202 congenital disorders of larynx.

4. K lensasser. M icrolaryngoscopy and endolaryngeal microsurgery (3rd ed), chapter 3, Examination of larynx. M osby Publishers 3-7.

\section{ABOUT THE AUTHORS}

\section{Harish Chandra Reddy Pingili (Corresponding Author)}

A ssistant Professor, D epartment of ENT, K akatiya M edical College W arangal, A ndhra Pradesh, India, e-mail: pharishreddy@yahoo.com

\section{S Ramesh Kumar}

Professor, Department of ENT, K akatiya M edical College, W arangal Andhra Pradesh, India 